Published in final edited form as:

Sci Signal. ; 10(505): . doi:10.1126/scisignal.aao2327.

\title{
The genetics of PKM $\zeta$ and memory maintenance
}

\author{
Todd Charlton Sacktor ${ }^{1,{ }^{*}}$ and Johannes W. Hell2, \\ ${ }^{1}$ Departments of Physiology \& Pharmacology, Anesthesiology, and Neurology, Robert F. Furchgott \\ Center for Neural and Behavioral Science, State University of New York Downstate Medical \\ Center, Brooklyn, NY 11203, USA \\ ${ }^{2}$ Department of Pharmacology, University of California, Davis, Davis, CA 95615, USA
}

\section{Abstract}

Elucidating the molecular mechanisms that maintain long-term memory is a fundamental goal of neuroscience. Accumulating evidence suggests that persistent signaling by the atypical protein kinase $\mathrm{C}(\mathrm{PKC})$ isoform protein kinase $\mathrm{M \zeta}(\mathrm{PKM} \zeta$ ) might maintain synaptic long-term potentiation (LTP) and long-term memory. However, the role of PKM $\zeta$ has been challenged by genetic data from PKM $\zeta$-knockout mice showing intact LTP and long-term memory. Moreover, the PKM $\zeta$ inhibitor peptide $\zeta$ inhibitory peptide (ZIP) reverses LTP and erases memory in both wild-type and knockout mice. Data from four papers using additional isoform-specific genetic approaches have helped to reconcile these conflicting findings. First, a PKM $\zeta$-antisense approach showed that LTP and longterm memory in PKM $\zeta$-knockout mice are mediated through a compensatory mechanism that depends on another ZIP-sensitive atypical isoform, $\mathrm{PKC} / \lambda$. Second, short hairpin RNAs decreasing the amounts of individual atypical isoforms without inducing compensation disrupted memory in different temporal phases. $\mathrm{PKC \imath} / \lambda$ knockdown disrupted short-term memory, whereas PKM $\zeta$ knockdown specifically erased long-term memory. Third, conditional $\mathrm{PKC} / \lambda$ knockout induced compensation by rapidly activating PKM $\zeta$ to preserve short-term memory. Fourth, a dominant-negative approach in the model system Aplysia revealed that multiple PKCs form PKMs to sustain different types of long-term synaptic facilitation, with atypical PKM maintaining synaptic plasticity similar to LTP. Thus, under physiological conditions, PKM $\zeta$ is the principal PKC isoform that maintains LTP and long-term memory. $\mathrm{PKC} / \lambda$ can compensate for PKM $\zeta$, and because other isoforms could also maintain synaptic facilitation, there may be a hierarchy of compensatory mechanisms maintaining memory if PKM $\zeta$ malfunctions.

Long-term memories are thought to be stored by persistent modifications in synaptic strength, which alter the connectivity of networks of neurons that underlie cognition and behavior $(1,2)$. However, most signaling events in neurons last only seconds to minutes. Those that last longer generally alter gene expression in the nucleus or other cell-wide processes (3). Because one neuron can be connected to thousands of other neurons, the signals that affect a neuron as a whole lack the ability to strengthen the synaptic connections between some neurons and not others, which is believed to be essential for encoding specific

\footnotetext{
*Corresponding author. tsacktor@ downstate.edu (T.C.S.); jwhell@ucdavis.edu (J.W.H.).
} 
memories in a network. Thus, identifying the persistent molecular mechanisms that modify transmission at synapses for hours to days and weeks after a brief stimulation is a major challenge for understanding how longterm memories are stored (4).

One approach to identify the signaling mechanisms that sustain enhanced synaptic strength is to study long-term potentiation (LTP)—a persistent, synapse-specific strengthening of excitatory transmission that is triggered by a brief but strong afferent stimulation (5). LTP can be divided into an early phase that exclusively requires post-translational modifications and a late phase that requires de novo protein synthesis (6). These two requirements are also the characteristic features of short-term and long-term memory $(3,7)$.

The core signaling mechanisms of early-LTP induction by trains of electric stimuli (tetani) are $\mathrm{Ca}^{2+}$ influx through $\mathrm{N}$-methyl-D-aspartate-type glutamate receptors (NMDARs) and the consequent stimulation of two main protein kinases, the $\mathrm{Ca}^{2+} /$ calmodulin-dependent protein kinase II (CaMKII) $(5,8)$ and protein kinase C (PKC) (9). CaMKII can directly phosphorylate postsynaptic AMPA-type glutamate receptors (AMPARs) to enhance their conductance and also promote trafficking of AMPARs to postsynaptic sites. Activation of CaMKII is limited to $\sim 1$ min after strong postsynaptic stimulation (10).

PKC is also activated by tetani, but its response to synaptic stimulation is complex because of the heterogeneity of PKC isoforms. PKC consists of a gene family divided into three classes: conventional PKCs $\alpha, \beta$, and $\gamma$; novel PKCs $\delta, \varepsilon, \eta$, and $\theta$; and atypical PKC $\zeta$ and $\mathrm{PKC} / \lambda$ (human $\mathrm{PKC} \imath$ and rodent $\mathrm{PKC} \lambda$ are orthologous genes) $(11,12)$. Most PKCs consist of a regulatory domain and a catalytic domain. The regulatory domain contains phospholipid and second messenger-binding sites and a pseudosubstrate sequence that helps maintain the catalytic domain in an inactive state. The various classes of PKC are activated by distinct second messengers that bind to the regulatory domain and release this autoinhibition. Conventional PKC isoforms are stimulated by $\mathrm{Ca}^{2+}$-triggered binding of anionic phospholipids to their $\mathrm{C} 2$ regulatory subdomains and by binding of diacylglycerol (DAG) to their $\mathrm{C} 1$ subdomains. Novel PKC isoforms require only DAG for their activation. In contrast, atypical PKC isoforms are activated by various mechanisms, including interaction with lipids such as phosphatidylinositol 3,4,5-trisphosphate ( $\left.\mathrm{PIP}_{3}\right)$ or ceramide through their unorthodox $\mathrm{C} 1$ regulatory subdomains, binding to other proteins, and phosphorylation of the activation loop by another kinase, phosphoinositide-dependent kinase 1 (PDK1). Thus, the full-length PKCs require a membrane phospholipid environment and second messengers to displace the auto-inhibitory pseudosubstrate segments for full activation, and these isoforms translocate from cytosol to membrane during this process. Because the second messengers are rapidly metabolized, the activation of most full-length PKCs in LTP is transient, lasting a few seconds to minutes (13).

\section{$\mathrm{PKC}_{2} / \lambda$ and Early LTP}

In contrast to CaMKII and the conventional/novel PKCs, the atypical $\mathrm{PKC} 2 / \lambda$ has a more persistent action in early LTP. Increases in $\mathrm{PKC \imath} / \lambda$ phosphorylation on its activation loop, as well as increases in total amount of $\mathrm{PKC} 2 / \lambda$, can last 1 hour after tetanization, returning to basal amounts after 3 hours $(14,15)$. The work of Ren et al. (16) has characterized the 
mechanism by which PKC $2 / \lambda$ augments synaptic transmission in early LTP by driving AMPARs to postsynaptic sites to enhance synaptic transmission (Fig. 1A). The peptide inhibitor $\zeta$ inhibitory peptide (ZIP) consists of a myristoylated version of the autoinhibitory pseudosubstrate amino acid sequence that is present in the regulatory domain of both PKC $\zeta$ and $\mathrm{PKC} 2 / \lambda$, and thus, ZIP blocks both PKM $\zeta$ (protein kinase $\mathrm{M} \zeta$ ) and $\mathrm{PKC} 2 / \lambda(15,16)$. ZIP- and short hairpin RNA (shRNA)-mediated knockdown of PKC $\lambda$ renders LTP very shortlived (16). Stimulation of phosphatidylinositol 3-kinase (PI3K), which is downstream of CaMKII and mitogen-activated protein kinase, produces $\mathrm{PIP}_{3}$, which leads to activation of PKC $\lambda$ and increases in post-synaptic AMPAR content and miniature excitatory postsynaptic current (mEPSC) and EPSC magnitude, thus mimicking LTP. All these effects are blocked by ZIP and PKC $/ \lambda$ knockdown. PI3K activation also stimulates phosphorylation of $\operatorname{Ser}^{818}$ in the AMPAR GluA1 subunit, an established PKC site, which contributes to LTP under some conditions (17) but not all (18). In detail, stimulation of PKC leads to phosphorylation of $\mathrm{Ser}^{818}$ in human embryonic kidney 293 cells, and ectopic expression of GluA1 with an S818A mutation impairs LTP induced by a pairing paradigm (17). It is tempting to speculate that phosphorylation of $\mathrm{Ser}^{818}$ is critical for postsynaptic targeting of homomeric AMPARs, which consist of four GluA1 subunits, rather than that of the more prevalent heterotetrameric GluA1/GluA2 receptors, with GluA1 homomers being required for LTP at certain but not all ages in rodents $(19,20)$.

On the other hand, PI3K binds to the AMPAR GluA2 subunit (21) and the protein p62, a versatile adaptor protein for various proteins including atypical PKC isoforms, which links PKC $\lambda$ to AMPARs (22). p62 is also known as sequestosome 1 because of its involvement in autophagy through its binding to polyubiquitinated proteins (23). Ren et al. (16) reported that stimulation of PI3K increases binding of p62 and PKC $\lambda$ to AMPARs, which is blocked by ZIP. Furthermore, knockdown of p62 impairs LTP. Membrane-permeant peptides mimicking the p62-binding site on GluA1 or the PKC2/ $\lambda$-binding site on p62 disrupt the respective interactions and block the increases in postsynaptic AMPAR content and EPSC magnitude by PI3K activation and pairing-induced LTP. In a model (Fig. 1A) for localized increases of postsynaptic AMPAR content mediated by the $\mathrm{Ca}^{2+}{ }^{2} \mathrm{PI} 3 \mathrm{~K}-\mathrm{p} 62 / \mathrm{PKC} 2 / \lambda$ pathway, the activity-triggered increase in the p62/PKC $\lambda$-AMPAR interaction recruits $\mathrm{PKC} \lambda$ to synapses for extended signaling by PKC $\lambda$ at these synapses. Because the inhibitors of this pathway suppress potentiation at tetanized synaptic pathways and not nontetanized control pathways, the effects of $\mathrm{PKC} 2 / \lambda$ may act at specific synapses, a critical property of LTP and learning. Because p62 binds to the atypical PKC regulatory domain that is not present in PKM $\zeta$ and full-length PKC $\zeta$ abundance is very low if not absent in the forebrain (24), PKC $\lambda$ is the only known candidate that can increase AMPAR activity in this p62-dependent manner.

\section{PKMS and Late LTP}

In contrast to the full-length PKC isoforms that are transiently active in early LTP, the nervous system-specific atypical isoform PKM $\zeta$ is persistently active in late LTP (25). $\mathrm{PKM} \zeta$ consists of an independent catalytic domain of PKC $\zeta$, which is autonomously active because it lacks the autoinhibitory pseudosubstrate in the $\zeta$ regulatory domain (13). PKM $\zeta$ is generated from a dedicated PKM $\zeta$ mRNA, which contains an open reading frame 
encoding only the $\zeta$ kinase domain that is transcribed by a neural tissue-specific internal promoter within the Prkcz gene (Fig. 1B) (24). The PKMS mRNA is constitutively transported to the dendrites of neurons (26). However, under basal conditions, the PKM mRNA is translationally repressed by multiple micro open reading frames in its long $5^{\prime}$ untranslated region, which prevent ribosomes from reaching and initiating translation of the open reading frame that encodes the kinase $(24,27)$. However, when LTP is triggered at synapses, $\mathrm{Ca}^{2+}$ influx through the activated NMDAR derepresses the PKMS mRNA through the concerted action of CaMKII, ERK, PI3K, PKA, and mechanistic target of rapamycin (mTOR) (14). The nascent PKM $\zeta$ is then fully activated through co-translational phosphorylation by PDK1 (14) and stabilized by signaling mechanisms downstream of brain-derived neurotrophic factor (28) and by binding to the protein KIBRA (29). The newly synthesized, autonomously active PKM $\zeta$ is then thought to be "tagged" to specific activated synapses, as shown by synaptic pathway-tagging experiments in hippocampal slices (30) and the translocation of newly synthesized PKM $\zeta$ to postsynaptic sites during chemically induced LTP of primary cultured neurons (31).

Three lines of evidence indicate that persistent signaling by the increased abundance of PKM $\zeta$ at synapses then maintains late LTP and long-term memory. First, the persistent increase in steady-state amounts of PKM $\zeta$ remains stable for hours after LTP induction in hippocampal slices $(15,25)$ and for days to weeks after learning in vivo, far longer than most other activity-dependent gene products, such as arc or fos (32). The extent of the persistent increase in PKM $\zeta$ abundance correlates with the degree of synaptic potentiation during LTP maintenance (25) and memory retention during long-term memory storage (32).

Second, the increase of PKM $\zeta$ at synapses is sufficient to enhance neurotransmission (9), and overexpression of the kinase enhances memory storage (33). Analysis of the enhanced synaptic transmission caused by the postsynaptic perfusion of PKM $\zeta$ reveals a single mechanism of synaptic potentiation-a doubling of the number of functional postsynaptic AMPARs (34). PKM $\zeta$ increases postsynaptic receptors by decreasing postsynaptic AMPAR endocytosis mediated by the trafficking protein $N$-ethylmaleimide-sensitive factor (NSF) through action on the GluA2 subunit of the receptor (35). Further evidence indicates that this mechanism of postsynaptic potentiation maintains both late LTP and long-term memory storage (35-39).

Third, multiple inhibitors of PKM $\zeta$ reverse LTP maintenance and disrupt established longterm memory. Two pharmacological PKM $\zeta$ inhibitors, the pseudosubstrate-based peptide ZIP and the small-molecule PKC inhibitor chelerythrine, reverse LTP maintenance when applied many hours after induction and erase long-term memory when applied days to weeks after training $(9,40-43)$. Overexpression of a dominant-negative mutated version of PKM $\zeta$ also disrupts established long-term memory (33). In contrast, a broad-spectrum kinase inhibitor, staurosporine, which inhibits conventional and novel PKCs and CaMKII at low doses but not PKM $\zeta$, blocks the induction but not the maintenance of LTP and longterm memory $(9,40)$. Furthermore, preventing the removal of AMPARs from postsynaptic sites by inhibiting postsynaptic GluA2 endocytosis blocks the ability of ZIP to reverse LTP maintenance and erase long-term memory $(36,37,44)$. These data support the notion that ZIP acts on PKM $\zeta$ to disrupt the persistence of LTP and memory. 


\section{PKMS-Knockout Mice: Controversy and Compensation}

However, genetic evidence from PKM $\zeta$-knockout mice cast doubt on the role of PKM $\zeta$ in LTP and memory $(45,46)$. First, without PKM $\zeta$, the knockout mice show intact late LTP and long-term memory. Second, the inhibitor ZIP reverses LTP and erases memory in PKM $\zeta$ null mice as it does in wild-type mice. These results clearly show that PKM $\zeta$ is not necessary for LTP or memory and that ZIP has off-target effects that disrupt these processes in the absence of PKM $\zeta$. Two hypotheses can explain these results. First, PKM $\zeta$ is unnecessary for LTP and memory, meaning ZIP acts on targets other than PKM $\zeta$. Second, PKM $\zeta$ is necessary for LTP and long-term memory in wild-type mice, and another molecule, which is also inhibited by ZIP, compensates for PKMS during LTP and memory in the knockout mice.

To distinguish between these hypotheses, Tsokas et al. (15) used a pharmacogenetic approach. Because the catalytic sites of PKC isoforms are very similar, most PKC inhibitors that compete for substrate binding, such as the pseudosubstrate ZIP, lack isoform specificity. In contrast, the nucleotide sequence of the translation start site in PKM $\mathrm{mRNA}$ contains sequences found in no other RNA (other than $P K C S$ mRNA). Tsokas and colleagues identified antisense oligonucleotides complementary to the PKM $\zeta$ translation site, which blocked the de novo synthesis of PKM $\zeta$ in wild-type mice without affecting the activitydependent synthesis of other gene products, including $\mathrm{PKC} 2 / \lambda$. Tsokas et al. then examined the effect of the PKM $\zeta$-antisense on LTP. They confirmed the previous findings of Volk et al. (46) that LTP in wild-type and PKM $\zeta$-knockout mice appeared identical. However, the PKM $\zeta$-antisense prevented late LTP only in the wild-type mice and not in the PKM $\zeta$-null mice (15). The PKM $\zeta$-antisense had the same differential effect on the two mouse genotypes when tested on spatial long-term memory. Thus, although LTP and spatial memory in the wild-type and PKM $\zeta$-knockout mice appear similar, their underlying molecular mechanisms are different.

To characterize the mechanism for the compensation in the PKM $\zeta$-null mice, Tsokas et al. analyzed the complete PKC isoform family in the hippocampus. The results revealed basal increases in two isoforms in the knockout mice-the conventional isoform PKC $\beta I$ and the atypical isoform $\mathrm{PKC} 2 / \lambda$. Both isoforms are activated in the early phase of LTP in wild-type animals, with PKC $\beta I$ activation lasting for seconds after synaptic stimulation (13) and $\mathrm{PKC} 2 / \lambda$ activation lasting about 1 hour (14). Because $\mathrm{PKC} 2 / \lambda$ is the most closely related PKC isoform to PKM $\zeta$, it was a likely candidate to compensate for PKM $\zeta$ in the knockout mice. To examine this possibility, Tsokas et al. first compared the activation of $\mathrm{PKC} / \lambda$ during LTP maintenance in wild-type and PKM $\zeta$-null mice. During late LTP in wild-type mice, the increases in $\mathrm{PKC} 2 / \lambda$ activation, as measured by increased $\mathrm{PKC} 2 / \lambda$ phosphorylation by PDK 1 and increased total amounts of $\mathrm{PKC} 2 / \lambda$, returned to baseline after 3 hours. In contrast, during late LTP in PKM $\zeta$-knockout mice, the increases in phosphorylated and total $\mathrm{PKC} / \lambda$ were maintained for at least 3 hours (Fig. 1C). To examine whether the persistent action of $\mathrm{PKC} 2 / \lambda$ maintains LTP and long-term memory, Tsokas et al. again used a pharmacogenetic approach, taking advantage of an allosteric $\mathrm{PKC} 2 / \lambda$-selective inhibitor. They found that the PKC $2 / \lambda$-selective inhibitor reversed late LTP and disrupted established spatial long-term memory in PKM $\zeta$-null mice but not wild-type mice. 
The double dissociation revealed from experiments with the $\mathrm{PKM} \zeta$-antisense and $\mathrm{PKC} 2 / \lambda$ inhibitor is consistent with the hypothesis that PKM $\zeta$ is important for LTP and long-term memory in wild-type mice and that compensatory mechanisms maintain these processes in PKM $\zeta$-knockout mice. The mechanism compensating for the loss of PKM $\zeta$ is to prolong the activation of $\mathrm{PKC} / \lambda$, which is important for early LTP in wild-type animals (16), into late LTP in the PKM $\zeta$-knockout mice (Fig. 1).

\section{Specific Functions of PKC $2 / \lambda$ and PKM $\zeta$ in LTP and Memory}

In a second study, Wang et al. (47) distinguished between the roles of PKC $2 / \lambda$ and $P K M \zeta$ in synaptic plasticity and memory by using shRNA to decrease the abundance of the isoforms individually. The viral expression of shRNA in the hippocampus reduced the amount of each isoform by $\sim 60$ to $75 \%$ without inducing a compensatory change in the other. When the amount of $\mathrm{PKC} 2 / \lambda$ was decreased before stimulation, early LTP and short-term memory were blocked, consistent with the studies of Ren et al. (16). Knockdown before stimulation also prevented the late phase of LTP and long-term memory. In contrast, when the amount of PKM $\zeta$ was decreased, early LTP and short-term memory were spared, and the late phase of LTP and long-term memory was specifically eliminated.

Because the PKC $/ \lambda$ knockdown affected short-term memory, it could have either prevented the induction of long-term memory or, if $\mathrm{PKC} \mathrm{r} / \lambda$ acted persistently in memory like $\mathrm{PKM} \zeta$, disrupted the maintenance of long-term memory. To distinguish between these possibilities, Wang et al. injected the viruses expressing PKC $2 / \lambda$ and PKM $\zeta$ shRNA several days after training and examined memory retention 1 month later. The results revealed that only the knockdown of PKM $\zeta$ and not $\mathrm{PKC} 2 / \lambda$ suppressed the storage of previously established long-term memory.

\section{Compensation for PKC $/ \lambda$ by PKM $\zeta$ in Mice with Conditional Knockout of $\operatorname{PKC} 2 / \lambda$}

Because global PKC $/ \lambda$-knockout mice are embryonically lethal (48), Sheng et al. (49) further examined $\mathrm{PKC} 2 / \lambda$ function in conditional knockout mice. They injected an adenoassociated virus (AAV) $P$ expressing Cre recombinase in the hippocampus of $\mathrm{PKC} 2 / \lambda$-floxed mice to reduce the amount of the isoform by 85 to $90 \%$. In contrast to pharmacological blockade or shRNA knockdown of PKC $2 / \lambda, \mathrm{PKC} 2 / \lambda$ conditional knockout mice showed early LTP and short-term memory. No changes in the basal abundance of PKM $\zeta$ were detected. However, on analysis of early LTP and short-term memory formation, Sheng et al. observed that $\mathrm{PKM} \zeta$ was formed more rapidly in $\mathrm{PKC} / \lambda$ conditional knockout mice than in wild-type mice, suggesting possible compensation (Fig. 1D).

To examine the function of PKM $\zeta$ in the PKC $2 / \lambda$ conditional knockout mice, Sheng and colleagues took advantage of previous findings that $\mathrm{PKC} 2 / \lambda$ and $\mathrm{PKM} \zeta$ enhance postsynaptic AMPAR-mediated transmission by different mechanisms of potentiation$\mathrm{PKC} 2 / \lambda$ by enhancing exocytosis through action on the GluA1 subunit (16) and PKM $\zeta$ by blocking endocytosis through NSF-GluA2 subunit interactions (35). Using an inhibitor of exocytosis and a peptide that blocks NSF-GluA2 interactions, Sheng et al. observed a double 
dissociation-early LTP in the wild-type mouse but not PKC $2 / \lambda$ conditional knockout mice required exocytosis, whereas early LTP in the $\mathrm{PKC} 2 / \lambda$ conditional knockout mice but not wild-type mice required NSF-GluA2 interactions. Thus, a compensatory switch in early LTP occurs in the $\mathrm{PKC} / \lambda$ conditional knockout mice from the synaptic potentiation mechanism of $\mathrm{PKC} 2 / \lambda$ to that of PKMS (Fig. 1D).

\section{Suboptimal Learning and Memory Produced by Compensation Between Atypical PKCs}

The knockout mouse studies revealed that each atypical PKC can compensate for the function of the other to preserve short- and long-term memory. However, if each isoform can mediate both phases of memory, then why are the roles of the two isoforms normally differentiated - with $\mathrm{PKC} / \lambda$ restricted to short-term memory and $\mathrm{PKM} \zeta$ to long-term memory? Tsokas et al. and Sheng et al. addressed this question by asking whether learning and memory in knockout mice with only a single atypical PKC might be worse than wildtype mice with both. To reveal possible deficits in behavior, Tsokas and colleagues (15) made memory formation progressively harder to acquire. First, on examining the ability of the mice to avoid a shock zone on a rotating platform, they decreased the duration of the training periods so that the acquisition of spatial memory accumulated slowly over several days rather than rapidly in a single day. The wild-type mice learned to avoid the shock zone by exploring the whole apparatus to find the safest location furthest from the shock zone. In contrast, the PKM $\zeta$-knockout mice avoided the shock by remaining in a region close to it, rarely moving from that location to explore the full apparatus, a relatively inefficient strategy that results in more shocks. Next, Tsokas et al. tested PKM $\zeta$-knockout and wild-type mice on a battery of learning and memory tasks that involves placing objects in novel locations and contexts. Whereas the PKM $\zeta$-knockout mice and wild-type mice performed the simple tasks equally well, the PKM $\zeta$-knockout mice could not learn or remember a complex version of the task involving multiple object-locations unlike the wild-type mice. In similar experiments on $\mathrm{PKC} / \lambda$ conditional knockout mice, Sheng et al. made hippocampusdependent versions of fear conditioning and spatial tasks more difficult by reducing the number of training trials (49). The $\mathrm{PKC} / \lambda$ conditional knockout mice performed worse than wild-type mice in the more difficult versions of both tasks.

Thus, mice with two atypical PKCs perform better in learning and memory tasks than those with only one. In cognitively complex tasks, multiple short-term memories might have to be integrated to determine the optimal strategy to be stored in long-term memory. Therefore, in the PKM $\zeta$-knockout mice, keeping short- and long-term memories separate might be problematic if only $\mathrm{PKC} / \lambda$ is available for both short- and long-term memory storage within neurons. Likewise, in the PKC $/ \lambda$ conditional knockout mice, rapid PKM $\zeta$ activation may not be as efficient or sensitive to stimulation as $\mathrm{PKC} 2 / \lambda$, such that only a few shortterm experiences might not be sufficient to encode a long-term memory. Thus, the advantages of separate, specialized atypical PKCs for storing short-term and long-term memories may provide selection pressure that maintains both atypical isoforms in vertebrate evolution. 


\section{A Plethora of PKMs}

The PKM $\zeta$-knockout mice show that the other atypical isoform, $\mathrm{PKC} / \lambda$, can compensate for the loss of PKM $\zeta$ by becoming persistently active to maintain late LTP and long-term memory. However, could persistent action of the conventional and novel PKCs also maintain long-term memory? Work in the invertebrate model system of learning and memory Aplysia californica suggests that they may (50). The mollusk $A$. californica produces a single isoform for each of the three PKC classes in neural tissue (50). The Aplysia-atypical PKC also forms a PKM by proteolytic cleavage of the full-length atypical PKC by calpain rather than through translation of a PKM $\zeta$ mRNA, a mechanism of PKM formation found only for PKM $\zeta$ in vertebrates $(51,52)$. In Aplysia, all three PKCs can form PKMs through cleavage by various forms of calpain (50).

Glanzman and colleagues showed that ZIP and chelerythrine erase behavioral long-term sensitization of siphon-withdrawal reflexes when the inhibitors are introduced into the nervous system of the animals 1 week after training (53). Both agents also reverse the maintenance of long-term facilitation of AMPAR-type glutamatergic synaptic transmission between cultured identified neurons, a form of synaptic plasticity that underlies the behavioral sensitization $(54,55)$.

Hu et al. (50) have identified the PKC isoforms that maintain the persistent synaptic enhancement. They examined two forms of longterm synaptic facilitation: the nonassociative form of plasticity studied by Glanzman, which is induced by the application of the neuromodulator serotonin, and an activity-dependent form induced by the combination of serotonin and synapse activation, which is thought to underlie classical conditioning and is similar to LTP. One day after the stimulation that produced the forms of long-term plasticity, they overexpressed dominant-negative versions of each PKM isoform either pre- or post-synaptically so as to localize the site of the persistent action of the PKM isoform in long-term maintenance.

In a remarkable example of conservation of function across phyla, blocking of the postsynaptic action of Aplysia-atypical PKM, which is the isoform most similar to vertebrate PKM $\zeta$, reversed the maintenance of the LTP-like, activity-dependent long-term facilitation (50). The dominant-negative atypical PKM also reversed nonassociative longterm facilitation when injected presynaptically. However, expression of a dominantnegative novel PKM also reversed the maintenance of both forms of long-term facilitation when overexpressed in the same sites. Conversely, expression of dominant-negative conventional PKM reversed maintenance when overexpressed in the complementary neurons — presynaptically in associative long-term facilitation and post-synaptically in nonassociative long-term facilitation. The reversal of specific forms of long-term synaptic facilitation by specific dominant-negative PKMs implied that PKC isoforms in Aplysia do not compensate for each other after the relatively rapid overexpression of the dominant negative PKMs. A second study by the same group found that atypical PKM and conventional PKM maintained associative and nonassociative forms of long-term plasticity, respectively, at distinct synapses even within the same postsynaptic neuron (56). Thus, the 
work in Aplysia suggests that multiple PKC isoforms, in addition to atypical PKC, can maintain long-term synaptic enhancement by forming persistently active PKMs.

\section{Conclusions}

These four studies using various genetic methods to examine PKC isoforms provide fundamental insights into the molecular mechanisms of memory maintenance and help resolve the controversy over PKM $\zeta$ in long-term memory storage, in which the pharmacological and dominant-negative data appeared to conflict with the knockout mouse data. The results of the pharmacogenetic analysis of the PKM $\zeta$-knockout and the shRNAmediated knockdown of PKM $\zeta$ demonstrated that PKM $\zeta$ is the principal PKC isoform maintaining LTP and long-term memory storage under physiological conditions in wild-type mice $(15,47)$. However, these findings, together with those from the $\mathrm{PKC} 2 / \lambda$ conditional knockout mice (49), also revealed that the heterogeneity of PKC isoforms provides flexibility to the molecular mechanisms that sustain the fundamental processes of LTP and memory. In the PKM $\zeta$-knockout mice, another atypical PKC that is also blocked by the inhibitors used to probe PKM $\zeta$ function, ZIP and chelerythrine, compensated for PKM $\zeta$ by extending its role in early LTP and shortterm memory into late LTP and long-term memory (15). The converse also occurred: In the PKC $/ \lambda$ conditional knockout mice, PKM $\zeta$ was activated more rapidly to compensate for the loss of PKC $2 / \lambda$ in early LTP and short-term memory (49). Compensation in memory function may not be restricted to the atypical PKCs. In the PKM $\zeta$-knockout mice, both $\mathrm{PKC} / \lambda$ and the conventional PKC $\beta \mathrm{I}$ increased in hippocampus (15). Moreover, studies of a model system with fewer PKC isoforms demonstrated that not only atypical PKC but also conventional and novel PKCs could form PKMs to sustain the long-term synaptic facilitation that underlies memory maintenance (50). The generality of PKM formation from any PKC isozyme raises the possibility that other forms of synaptic plasticity and memory not yet characterized could be sustained by the persistent action of different PKCs.

The common feature linking all the physiological and compensatory PKC isoform-specific mechanisms is that the persistent action of the isoform sustains the maintenance of the memory. Thus, the genetic studies raise the fundamental question of the nature of the mechanisms by which persistent increases in autonomously active PKM $\zeta$ can be sustained for weeks (32). Is the persistence due to increased PKM $\zeta$ synthesis or decreased degradation? How might these mechanisms result in persistent increases in the kinase that remain compartmentalized to specific synapses? How many synapses contain PKM $\zeta$ to store a memory? Are there mechanisms to keep its distribution sparse, so as not to "saturate" the synapses of a neuron with PKM $\zeta$ as more memories are stored? Do PKC $2 / \lambda$ or PKMs of other isozymes use isoform-specific mechanisms for maintenance, or do they engage a common set of maintenance mechanisms when PKM $\zeta$ is no longer available? Which proteins are the relevant targets for phosphorylation by these kinases? Epigenetic changes are also implicated in long-term memory maintenance $(57,58)$. PKM $\zeta$ may act both upstream and downstream in these epigenetic mechanisms. Phosphorylation by nuclear PKM $\zeta$ maintains histone acetylation during memory storage (59), and decreased DNA methylation of the Prkcz gene after memory formation leads to increase amounts of PKMS mRNA (60). How might the epigenetic regulation of PKM $\zeta$ and the nuclear effects of 
PKM $\zeta$ interact with its role in synaptic potentiation? Addressing these questions in future studies of PKM $\zeta$ and compensating PKCs will lead to an even deeper understanding of how long-term memories are stored.

\section{REFERENCES AND NOTES}

1. Whitlock JR, Heynen AJ, Shuler MG, Bear MF, Learning induces long-term potentiation in the hippocampus. Science 313, 1093-1097 (2006). [PubMed: 16931756]

2. Morris RGM, NMDA receptors and memory encoding. Neuropharmacology 74, 32-40 (2013). [PubMed: 23628345]

3. Alberini CM, Kandel ER, The regulation of transcription in memory consolidation. Cold Spring Harb. Perspect. Biol. 7, a021741 (2014). [PubMed: 25475090]

4. Crick F, Memory and molecular turnover. Nature 312, 101 (1984). [PubMed: 6504122]

5. Huganir RL, Nicoll RA, AMPARs and synaptic plasticity: The last 25 years. Neuron 80, 704-717 (2013). [PubMed: 24183021]

6. Frey U, Krug M, Reymann KG, Matthies H, Anisomycin, an inhibitor of protein synthesis, blocks late phases of LTP phenomena in the hippocampal CA1 region in vitro. Brain Res. 452, 57-65 (1988). [PubMed: 3401749]

7. Davis HP, Squire LR, Protein synthesis and memory: A review. Psychol. Bull. 96, 518-559 (1984). [PubMed: 6096908]

8. Hell JW, CaMKII: Claiming center stage in postsynaptic function and organization. Neuron 81 , 249-265 (2014). [PubMed: 24462093]

9. Ling DSF, Benardo LS, Serrano PA, Blace N, Kelly MT, Crary JF, Sacktor TC, Protein kinase M $\zeta$ is necessary and sufficient for LTP maintenance. Nat. Neurosci. 5, 295-296 (2002). [PubMed: 11914719]

10. Murakoshi H, Shin ME, Parra-Bueno P, Szatmari EM, Shibata ACE, Yasuda R, Kinetics of endogenous CaMKII required for synaptic plasticity revealed by optogenetic kinase inhibitor. Neuron 94, 37-47.e5 (2017). [PubMed: 28318784]

11. Callender JA, Newton AC, Conventional protein kinase C in the brain: 40 years later. NeuronalSignaling 1, NS20160005 (2017).

12. Mochly-Rosen D, Das K, Grimes KV, Protein kinase C, an elusive therapeutic target? Nat. Rev. Drug Discov. 11, 937-957 (2012). [PubMed: 23197040]

13. Sacktor TC, Osten P, Valsamis H, Jiang X, Naik MU, Sublette E, Persistent activation of the Z isoform of protein kinase $\mathrm{C}$ in the maintenance of long-term potentiation. Proc. Natl. Acad. Sci. U.S.A. 90, 8342-8346 (1993). [PubMed: 8378304]

14. Kelly MT, Crary JF, Sacktor TC, Regulation of protein kinase MS synthesis by multiple kinases in long-term potentiation. J. Neurosci. 27, 3439-3444 (2007). [PubMed: 17392460]

15. Tsokas P, Hsieh C, Yao Y, Lesburguères E, Wallace EJC, Tcherepanov A, Jothianandan D, Hartley BR, Pan L, Rivard B, Farese RV, Sajan MP, Bergold PJ, Hernández AI, Cottrell JE, Shouval HZ, Fenton AA, Sacktor TC, Compensation for PKM $\zeta$ in long-term potentiation and spatial long-term memory in mutant mice. eLife 5, e14846 (2016). [PubMed: 27187150]

16. Ren S-Q, Yan J-Z, Zhang X-Y, Bu Y-F, Pan W-W, Yao W, Tian T, Lu W, PKC $\lambda$ is critical in AMPA receptor phosphorylation and synaptic incorporation during LTP. EMBO J. 32, 1365-1380 (2013). [PubMed: 23511975]

17. Boehm J, Kang M-G, Johnson RC, Esteban J, Huganir RL, Malinow R, Synaptic incorporation of AMPA receptors during LTP is controlled by a PKC phosphorylation site on GluR1. Neuron 51, 213-225 (2006). [PubMed: 16846856]

18. Granger AJ, Shi Y, Lu W, Cerpas M, Nicoll RA, LTP requires a reserve pool of glutamate receptors independent of subunit type. Nature 493, 495-500 (2013). [PubMed: 23235828]

19. Lu Y, Allen M, Halt AR, Weisenhaus M, Dallapiazza RF, Hall DD, Usachev YM, McKnight GS, Hell JW, Age-dependent requirement of AKAP150-anchored PKA and GluR2-lacking AMPA receptors in LTP. EMBO J. 26, 4879-4890 (2007). [PubMed: 17972919] 
20. Hell JW, Evaluation of Granger et al. Nature 493, 495-500. F1000Prime, eval 793471654 (2013). [PubMed: 23235828]

21. Man H-Y, Wang Q, Lu W-Y, Ju W, Ahmadian G, Liu L, D’Souza S, Wong TP, Taghibiglou C, Lu J, Becker LE, Pei L, Liu F, Wymann MP, MacDonald JF, Wang YT, Activation of PI3-kinase is required for AMPA receptor insertion during LTP of mEPSCs in cultured hippocampal neurons. Neuron 38, 611-624 (2003). [PubMed: 12765612]

22. Jiang J, Parameshwaran K, Seibenhener ML, Kang M-G, Suppiramaniam V, Huganir RL, DiazMeco MT, Wooten MW, AMPA receptor trafficking and synaptic plasticity require SQSTM1/p62. Hippocampus 19, 392-406 (2009). [PubMed: 19004011]

23. Bjørkøy G, Lamark T, Brech A, Outzen H, Perander M, Øvervatn A, Stenmark H, Johansen T, p62/ SQSTM1 forms protein aggregates degraded by autophagy and has a protective effect on huntingtin-induced cell death. J. Cell Biol. 171, 603-614 (2005). [PubMed: 16286508]

24. Hernandez AI, Blace N, Crary JF, Serrano PA, Leitges M, Libien JM, Weinstein G, Tcherapanov A, Sacktor TC, Protein kinase M $\zeta$ synthesis from a brain mRNA encoding an independent protein kinase $C \zeta$ catalytic domain. Implications for the molecular mechanism of memory. J. Biol. Chem. 278, 40305-40316 (2003). [PubMed: 12857744]

25. Osten P, Valsamis L, Harris A, Sacktor TC, Protein synthesis-dependent formation of protein kinase MS in long-term potentiation. J. Neurosci. 16, 2444-2451 (1996). [PubMed: 8786421]

26. Muslimov IA, Nimmrich V, Hernandez AI, Tcherepanov A, Sacktor TC, Tiedge H, Dendritic transport and localization of protein kinase M $\mathrm{mRNA}$ : Implications for molecular memory consolidation. J. Biol. Chem. 279, 52613-52622 (2004). [PubMed: 15371429]

27. Bal NV, Susorov D, Chesnokova E, Kasianov A, Mikhailova T, Alkalaeva E, Balaban PM, Kolosov $\mathrm{P}$, Upstream open reading frames located in the leader of protein kinase $\mathrm{M} \zeta \mathrm{mRNA}$ regulate its translation. Front. Mol. Neurosci. 9, 103 (2016). [PubMed: 27790092]

28. Mei F, Nagappan G, Ke Y, Sacktor TC, Lu B, BDNF facilitates L-LTP maintenance in the absence of protein synthesis through PKMS. PLOS ONE 6, e21568 (2011). [PubMed: 21747912]

29. Vogt-Eisele A, Krüger C, Duning K, Weber D, Spoelgen R, Pitzer C, Plaas C, Eisenhardt G, Meyer A, Vogt G, Krieger M, Handwerker E, Wennmann DO, Weide T, Skryabin BV, Klugmann M, Pavenstädt H, Huentelmann MJ, Kremerskothen J, Schneider A, KIBRA (KIdney/BRAin protein) regulates learning and memoryand stabilizes protein kinase MS. J. Neurochem. 128, 686-700 (2014). [PubMed: 24117625]

30. Sajikumar S, Navakkode S, Sacktor TC, Frey JU, Synaptic tagging and cross-tagging: The role of protein kinase $\mathrm{M} \zeta$ in maintaining long-term potentiation but not long-term depression. J. Neurosci. 25, 5750-5756 (2005). [PubMed: 15958741]

31. Palida SF, Butko MT, Ngo JT, Mackey MR, Gross LA, Ellisman MH, Tsien RY, PKM $\zeta$, but not $\mathrm{PKC} \lambda$, is rapidly synthesized and degraded at the neuronal synapse. J. Neurosci. 35, 7736-7749 (2015). [PubMed: 25995463]

32. Hsieh C, Tsokas P, Serrano P, Hernández AI, Tian D, Cottrell JE, Shouval HZ, Fenton AA, Sacktor TC, Persistent increased PKM $\zeta$ in long-term and remote spatial memory. Neurobiol. Learn. Mem. 138, 135-144 (2017). [PubMed: 27417578]

33. Shema R, Haramati S, Ron S, Hazvi S, Chen A, Sacktor TC, Dudai Y, Enhancement of consolidated long-term memory by overexpression of protein kinase $\mathrm{M} \zeta$ in the neocortex. Science 331, 1207-1210 (2011). [PubMed: 21385716]

34. Ling DSF, Benardo LS, Sacktor TC, Protein kinase MS enhances excitatory synaptic transmission by increasing the number of active postsynaptic AMPA receptors. Hippocampus 16,443-452 (2006). [PubMed: 16463388]

35. Yao Y, Kelly MT, Sajikumar S, Serrano P, Tian D, Bergold PJ, Frey JU, Sacktor TC, PKMS maintains late long-term potentiation by $N$-ethylmaleimide-sensitive factor/GluR2-dependent trafficking of postsynaptic AMPA receptors. J. Neurosci. 28, 7820-7827 (2008). [PubMed: 18667614]

36. Migues PV, Hardt O, Wu DC, Gamache K, Sacktor TC, Wang YT, Nader K, PKM memories by regulating GluR2-dependent AMPA receptor trafficking. Nat. Neurosci. 13, 630-634 (2010). [PubMed: 20383136] 
37. Dong Z, Han H, Li H, Bai Y, Wang W, Tu M, Peng Y, Zhou L, He W, Wu X, Tan T, Liu M, Wu X, Zhou W, Jin W, Zhang S, Sacktor TC, Li T, Song W, Wang YT, Long-term potentiation decay and memory loss are mediated by AMPAR endocytosis. J. Clin. Invest. 125, 234-247 (2015). [PubMed: 25437879]

38. Migues PV, Hardt O, Finnie P, Wang YW, Nader K, The maintenance of long-term memory in the hippocampus depends on the interaction between $N$-ethylmaleimide-sensitive factor and GluA2. Hippocampus 24, 1112-1119 (2014). [PubMed: 24753224]

39. Migues PV, Liu L, Archbold GEB, Einarsson EÖ, Wong J, Bonasia K, Ko SH, Wang YT, Hardt O, Blocking synaptic removal of GluA2-containing AMPA receptors prevents the natural forgetting of long-term memories. J. Neurosci. 36,3481-3494 (2016). [PubMed: 27013677]

40. Pastalkova E, Serrano P, Pinkhasova D, Wallace E, Fenton AA, Sacktor TC, Storage of spatial information by the maintenance mechanism of LTP. Science 313, 1141-1144 (2006). [PubMed: 16931766]

41. Shema R, Sacktor TC, Dudai Y, Rapid erasure of long-term memory associations in cortex by an inhibitor of PKMS. Science 317, 951-953 (2007). [PubMed: 17702943]

42. Shema R, Hazvi S, Sacktor TC, Dudai Y, Boundary conditions for the maintenance of memory by PKMS in neocortex. Learn. Mem. 16, 122-128 (2009). [PubMed: 19181618]

43. Serrano P, Friedman EL, Kenney J, Taubenfeld SM, Zimmerman JM, Hanna J, Alberini C, Kelley AE, Maren S, Rudy JW, Yin JCP, Sacktor TC, Fenton AA, PKMS maintains spatial, instrumental, and classically conditioned long-term memories. PLOS Biol. 6, 2698-2706 (2008). [PubMed: 19108606]

44. Pauli WM, Clark AD, Guenther HJ, O’Reilly RC, Rudy JW, Inhibiting PKM $\zeta$ reveals dorsal lateral and dorsal medial striatum store the different memories needed to support adaptive behavior. Learn. Mem. 19, 307-314 (2012). [PubMed: 22723053]

45. Lee AM, Kanter BR, Wang D, Lim JP, Zou ME, Qiu C, McMahon T, Dadgar J, Fischbach-Weiss SC, Messing RO, Prkcz null mice show normal learning and memory. Nature 493, 416-419 (2013). [PubMed: 23283171]

46. Volk LJ, Bachman JL, Johnson R, Yu Y, Huganir RL, PKM- $\zeta$ is not required for hippocampal synaptic plasticity, learning and memory. Nature 493, 420-423 (2013).

47. Wang S,Sheng T, Ren S, Tian T,Lu W, Distinct roles of PKC $2 / \lambda$ and PKM $\zeta$ in the initiation and maintenance of hippocampal long-term potentiation and memory. Cell Rep. 16, 1954-1961 (2016). [PubMed: 27498875]

48. Seidl S, Braun U, Roos N, Li S, LQdtke TH-W, Kispert A, Leitges M, Phenotypical analysis of atypical PKCs in vivo function display a compensatory system at mouse embryonic day 7.5. PLOS ONE 8, e62756 (2013). [PubMed: 23690951]

49. Sheng T, Wang S, Qian D, Gao J, Ohno S, Lu W, Learning-induced suboptimal compensation for $\mathrm{PKC} 2 / \lambda$ function in mutant mice. Cereb. Cortex 27, 3284-3293 (2017). [PubMed: 28383692]

50. Hu J, Adler K, Abi Farah C, Hastings MH, Sossin WS, Schacher S, Cell-specific PKM isoforms contribute to the maintenance of different forms of persistent long-term synaptic plasticity. J. Neurosci. 37, 2746-2763 (2017). [PubMed: 28179558]

51. Bougie JK, Cai D, Hastings M, Farah CA, Chen S, Fan X, McCamphill PK, Glanzman DL, Sossin WS, Serotonin-induced cleavage of the atypical protein kinase C Apl III in Aplysia. J. Neurosci. 32, 14630-14640 (2012). [PubMed: 23077049]

52. Bougie JK, Lim T, Farah CA, Manjunath V, Nagakura I, Ferraro GB, Sossin WS, The atypical protein kinase C in Aplysia can form a protein kinase M by cleavage. J. Neurochem. 109, 11291143 (2009). [PubMed: 19302474]

53. Cai D, Pearce K, Chen S, Glanzman DL, Protein kinase M maintains long-term sensitization and long-term facilitation in Aplysia. J. Neurosci. 31, 6421-6431 (2011). [PubMed: 21525283]

54. Villareal G, Li Q, Cai D, Fink AE, Lim T, Bougie JK, Sossin WS, Glanzman DL, Role of protein kinase $\mathrm{C}$ in the induction and maintenance of serotonin-dependent enhancement of the glutamate response in isolated siphon motor neurons of Aplysia californica. J. Neurosci. 29, 5100-5107 (2009). [PubMed: 19386905]

55. Chitwood RA, Li Q, Glanzman DL, Serotonin facilitates AMPA-type responses in isolated siphon motor neurons of Aplysia in culture. J. Physiol. 534, 501-510 (2001). [PubMed: 11454967] 
56. Hu J, Ferguson L, Adler K, Farah CA, Hastings MH, Sossin WS, Schacher S, Selective erasure of distinct forms of long-term synaptic plasticity underlying different forms of memory in the same postsynaptic neuron. Curr. Biol. 27, 1888-1899 (2017). [PubMed: 28648820]

57. Day JJ, Sweatt JD, Cognitive neuroepigenetics: A role for epigenetic mechanisms in learning and memory. Neurobiol. Learn. Mem. 96, 2-12 (2011). [PubMed: 21195202]

58. Pearce K, Cai D, Roberts AC, Glanzman DL, Role of protein synthesis and DNA methylation in the consolidation and maintenance of long-term memory in Aplysia. eLife 6, e18299 (2017). [PubMed: 28067617]

59. Ko H-G, Kim J.-i., Sim S-E, Kim T, Yoo J, Choi S-L, Baek SH, Yu W-J, Yoon J-B, Sacktor TC, Kaang B-K, The role of nuclear PKMS in memory maintenance. Neurobiol. Learn. Mem. 135, 5056 (2016). [PubMed: 27321162]

60. Chen C, Meng S-Q, Xue Y-X, Han Y, Sun C-Y, Deng J-H, Chen N, Bao Y-P, Zhang F-L, Cao L-L, Zhu W-G, Shi J, Song W-H, Lu L, Epigenetic modification of PKM $\zeta$ rescues aging-related cognitive impairment. Sci. Rep. 6, 22096 (2016). [PubMed: 26926225] 


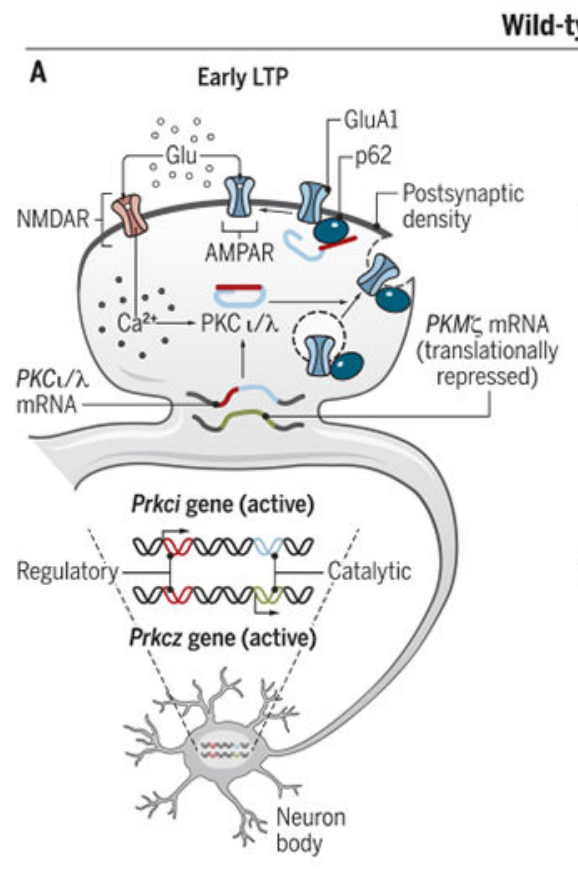

Wild-type

B Late LTP

PKM६-null
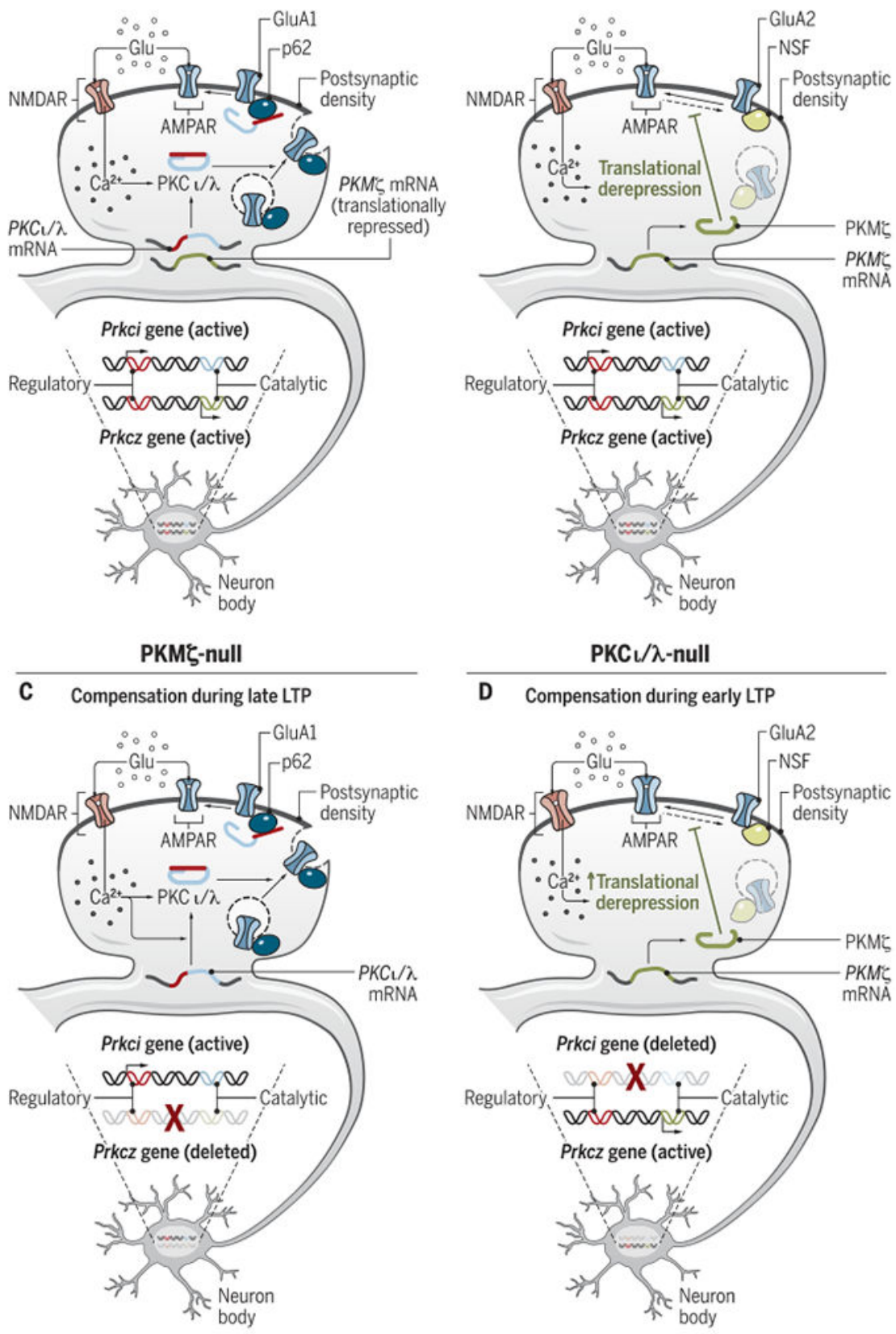

Fig. 1. Two distinct atypical PKCs mediate synaptic potentiation In early LTP and late LTP that allows for compensation in knockout mice.

(A) In one mechanism of early LTP in wild-type mice, NMDAR activation by weak afferent stimulation induces activation of $\mathrm{PKC} 2 / \lambda$ that potentiates synaptic transmission by enhancing exocytosis of AMPARs through p62 and action on the GluA1 subunit of the AMPAR. (B) In late LTP in wild-type mice, NMDAR activation by strong afferent stimulation induces derepression of PKM $\zeta$ mRNA, increasing de novo synthesis of PKM $\zeta$. PKM $\zeta$ enhances synaptic transmission by blocking endocytosis of postsynaptic AMPARs by 
the trafficking protein NSF through action on the GluA2 subunit. (C) In late LTP in PKMSknockout mice, the persistent increase in $\mathrm{PKC} / \lambda$ induced through activity-dependent synthesis of the kinase maintains synaptic potentiation. Whether the mechanism of late LTP synaptic potentiation in PKM $\zeta$-knockout mice is the same as early LTP in wild-type mice, as shown, is not known. (D) In early LTP in conditional PKC $/ \lambda$-knockout mice, $P K M S$ mRNA is derepressed more rapidly than in wild-type mice, leading to earlier synthesis of PKM $\zeta$. The mechanism of synaptic potentiation in early LTP in PKC $/ / \lambda$-knockout mice switches from GluA1 exocytosis to blocking endocytosis of postsynaptic AMPARs by the trafficking protein NSF through action on the GluA2 subunit, which is the expression mechanism mediated by PKM $\zeta$ in late LTP in wild-type mice. 